\title{
Who Should Provide Breastfeeding Education to Improve Success: A Midwife or a Physician?
}

\author{
Elif YILMAZ1, Zehra VURAL YILMAZ ${ }^{1}$, Mehmet FATİH KARSLI ${ }^{1}$, Meryem CEYHAN¹, Fatma DOĞ ÖCAL ${ }^{1}$, \\ Tuncay KÜÇÜKÖZKAN' ${ }^{1}$
}

Ankara, Turkey

\begin{abstract}
OBJECTIVE: The purpose of this study was to explore whether there was any difference in the breastfeeding success of mothers prior to hospital discharge who were given breastfeeding education by a physician (obstetrician-gynecologist) and a midwife with respect to the person giving the training.
\end{abstract}

STUDY DESIGN: The study was conducted between May- June 2015 on 200 mothers who gave their first full-term birth at the obstetrics and gynecology clinic of a tertiary hospital. The mothers were divided into two groups and each mother was explained the benefits of breastfeeding and given breastfeeding education when they became stabile in their beds after birth. One hundred of the mothers were trained by a midwife who received lactation consultancy training and the other hundred mothers by an obstetrician who also had the same training. After the education, each mother was observed while breastfeeding her baby by an investigator who also received lactation consultancy training, other than the ones who gave the training and the LATCH breastfeeding assessment tool was filled out. After calculating the LATCH score of each mother, the two groups were compared for their success in breastfeeding during discharge from the hospital with respect to the person giving the training.

RESULTS: There were no differences between the two mother groups in terms of demographic characteristics (age, education, occupation etc.) and newborn characteristics (weight, gender) ( $p>0.05)$. The total LACTH score was found higher in the group that was trained by a midwife than in the group that was trained by a physician $(p<0.05)$. An assessment of the LATCH sub-scores showed that the "holding the baby" score was similar in both groups $(p=0.502)$, but the other subgroup scores were higher again in the group that was trained by a midwife $(p<0.05)$.

CONCLUSION: The mothers who were trained in lactation by midwives were observed to be more successful in breastfeeding their babies than the mothers who were trained by a physician. Our opinion in this respect is that obstetricians should integrate trained midwives in breastfeeding education and in this way try to correct their deficiencies in this area.

Keywords: Breastfeeding education, LATCH, Midwife, Physician

Gynecol Obstet Reprod Med 2017;23(1):14-19

\section{${ }^{I}$ Dr. Sami Ulus Women's and Children's Health Training and Research Hospital Department of Obstetrics and Gynaecology, Ankara \\ Address of Correspondence: Zehra Vural Yllmaz \\ Dr. Sami Ulus Women's and Children's \\ Health Training and Research Hospital, \\ Department of Obstetrics and \\ Gynaecology Ankara, Turkey \\ zehravural@gmail.com \\ Submitted for Publication: $\quad$ 26.07.2016 \\ Accepted for Publication: $\quad 19.10 .2016$}

\begin{tabular}{|c|c|}
\hline \multicolumn{2}{|c|}{ Access this article online } \\
\hline $\begin{array}{l}\text { Quick Response Code: } \\
\text { Ryser }\end{array}$ & Website: www.gorm.com.tr \\
\hline 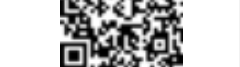 & DOI:10.201613/GORM.2016.628 \\
\hline
\end{tabular}

How to cite this article: Yllmaz E. Vural Yllmaz Z. Karsl MF. Ceyhan M. Doğa Öcal F. Küçüközkan T. Who Should Provide Breastfeeding Education to Improve Success: A Midwife or a Physician? Gynecol Obstet Reprod Med 2017;23(1):14-19

\section{Introduction}

Breast milk is an easy-to-digest, natural nutrient with high bioavailability, which contains all the liquid, energy, and nutrition elements that are necessary for optimum growth and development for a newborn. Breastfeeding have numerous benefits for the mother and the baby first in nourishment, health and immunity, and then in developmental, psychological, social, and economical areas (1,2,3). Despite all its significance, the frequency and duration of breastfeeding are still not at a desired level especially in a large number of developing countries. Although $96 \%$ of all children in Turkey seems to have been breastfed for some time, the rate of being fed exclusively with breast milk in the first six months dropped from $41.6 \%$ in 2008 to $30.1 \%$ in 2013 (4). Breastfeeding is not only a physiological event but a process that should be learned and 
the health professionals are largely responsible for initiating and continuing this process immediately after birth. Evaluating the breastfeeding statuses of mothers and providing them with good breastfeeding education by a lactation consultant in the short time they stay at the hospital is important in initiating breastfeeding, ensuring continuity in breastfeeding by preventing breastfeeding problems and increasing breastfeeding success $(5,6)$. Mothers should be informed about the benefits of breast milk, taught about breastfeeding techniques, encouraged to feed their children exclusively with breast milk and trained to avoid circumstances that would affect this negatively.

Early initiation of breastfeeding and getting support from the healthcare staff in this early period positively affects mother infant interaction and increases mother's favorable feelings about breastfeeding. Delayed initiation of breastfeeding has been associated with shorter breastfeeding duration $(7,8,9)$. According to existing literature, we can identify those women most at risk of initiating and then prematurely discontinuing breastfeeding prior to their hospital discharge with the attention of healthcare staff and support in this matter.

The present study was conducted to explore whether there was any difference in the breastfeeding success of the mothers prior to hospital discharge who were given breastfeeding education by a physician or a midwife, both of whom have received lactation consultancy education, with respect to the person who giving the training.

\section{Material And Method}

\section{Participants}

This prospective descriptive study was conducted between May-June 2015 at the Obstetrics and Gynecology Clinic of a maternity hospital, which generally serves to a profile of low education and income level, in Ankara, Turkey. The study sample consisted of 200 mothers who gave their first full-term births at the obstetrics clinic of the hospital.

Mothers were excluded if they had multiple pregnancies, preterm births ( $<37$ weeks), had serious complications during the ante/postpartum period (systemic diseases, preeclampsia, diabetes, postpartum bleeding) as well as those who were multiparous. Babies were excluded if they had postpartum health problems, required neonatal intensive care unit (NICU) treatment or intubation. This study was approved by the local Ethics Committee and written informed consent was obtained from each participant.

\section{Data collection}

The socio-demographic data of the patients were obtained by face to face interview using a questionnaire which included questions about age, educational level and working status of the patient and her spouse, total monthly income, health insurance and regular antepartum care.
The LATCH Breastfeeding Assessment Scale used in the study was developed by Jensen, Wallace and Kelsay in 1994 and its reliability in our country was ascertained through the studies carried out by Koyun (2001), Yenal and Okumuş (2003) $(10,11,12)$. This measurement tool consists of five assessment criteria. LATCH represents the combination of the first letters of the English words for these five criteria. From these criteria, L- (Latch) stands how the baby holds nipple in mouth, A- (Audible swallowing) for hearing the swallowing sound of the baby, T- Type of nipple (self-confidence of the mother about her nipple shape-lack of concern about the size or figure of the nipple), C- for Comfort (of the mother concerning her breast) and $\mathrm{H}$ - (Hold/Positioning) for the assistance required by the mother to position her baby for sucking. Scores between 0 and 2 are given for each item. The highest score obtainable is 10 .

The lactation counseling training of healthcare staff in our country is given by Children, Adolescent and Women's Reproductive Health Services Department which is affiliated to public health directorate. It is a standard certified training that lasts 4 days and include topics about the importance of breastmilk and its content, correct storing of breastmilk, the physiology of lactation, correct breastfeeding and milking techniques, problems with breast and nipple, evaluation of breastfeeding, relaxation, causes of insufficient milk and proper assistance to the mothers and babies having problem in breastfeeding.

On certain three days of the week (monday-wednesday-friday), after filling the socio demographic information form with face to face interview, the mothers who gave birth on the respective day were given breastfeeding education by a midwife who had lactation counseling training (group 1). On the other days of the week (Tuesday-Thursday-Saturday), the mothers who gave birth on the respective day were asked to fill out the questionnaire and given education by an obstetrician this time, who had the same training (group 2). Care was taken to give the trainings after the mothers' conditions became stable following the birth to ensure trainings were graspable. The contents of the training included the benefits of breast milk, how long exclusively breast milk should be given, the time to introduce additional foods, holding the baby right and positioning it correctly towards the breast, correct supporting of the breast, breastfeeding positions, indications of good and effective sucking, baby reactions, and the problems that may occur in the nipple and solutions to these which lasted about half an hour. Before the education, a list (a copy of which was also present in the trainer) including the topics and the duration of them were given to the mothers in order to avoid the differences between the groups. After the education of each mother, the trainer marked the topics she told and the total duration she spent for the educations of each mother in order to ensure consistency between the educations of the mothers (same contents, amount and duration). 
At the second stage, all mothers were observed when breastfeeding their babies by a different investigator (who also had the same lactation counseling training) from the midwife/obstetrician giving the training. It was made certain that all mothers were observed by the same investigator and the LATCH scales were filled out by this same investigator who was unaware of the person providing the education (blinded). Since mothers could be flurry and excited during their first breastfeeding following the training, they were left alone (family members/supporters were not allowed to be with patients during this time) and the second breastfeeding was used to observe them and complete the scale. As it is difficult to assess mother's knowledge about the insignificance of the type of nipple and the size/shape of breast on the success of breastfeeding by observation, they were evaluated by asking to the mothers. After calculating the LATCH score of each mother, the two groups (group 1-who were educated by the midwife and group 2- who were educated by the obstetrician) were compared for their success with respect to the person giving the training.

\section{Statistical Analyses}

All data was analyzed using the PASW Statistics Version 18.0 (SPSS, Chicago, IL, USA). Results are shown as means \pm SD (standard deviation) and $\mathrm{n}(\%)$. Parametric variables were compared using Student's t-test, and nonparametric vari- ables were compared by the Mann-Whitney U-test. Differences between the groups were assessed using a $\chi 2$ test for categorical variables. A value of $\mathrm{p}<0.05$ was considered to indicate statistical significance.

\section{Results}

\section{Socio-demographic characteristics}

The mean age of participating mothers was $24.2 \pm 4.2$ ( $\mathrm{min}$ 20-max 35 ages) with $24.0 \pm 4.3$ in Group 1 (midwife group) and $24.2 \pm 4.0$ in Group 2 (obstetrician group) ( $\mathrm{p}=0.738$ ). $65.7 \%$ of the mothers were primary school graduates, $24.4 \%$ of them high school graduates and $9.5 \%$ college graduates. $94 \%$ of the mothers had health insurance. While $87 \%$ of them were employed, 13\% were housewives.

The socio-demographic characteristics of the mothers are shown in Table 1 and no statistically significant differences were found between the two groups in terms of their education and employment status, education and employment status of their husbands, health insurance, monthly income and the rate of regular check-ups during pregnancy $(p>0.05)$.

The mean birth weight of babies was $3287 \pm 397.5$ (min 2500-max 4470, grams) with 3277.4 \pm 416.1 in Group 1 and $3296.7 \pm 379.8$ in Group $2(p=0.732)$. When the genders of the

Table 1. Comparison of the demographic features of the groups

\begin{tabular}{|c|c|c|c|}
\hline Features & Group 1 n (\%) & Group 2 n (\%) & $p$ \\
\hline Education Level & & & 0.659 \\
\hline Elementary school & $69(69)$ & $63(63)$ & \\
\hline High school & $22(22)$ & $27(27)$ & \\
\hline University & $9(9)$ & $10(10)$ & \\
\hline Employment Status & & & 0.834 \\
\hline Employed & $14(14)$ & $12(12)$ & \\
\hline Unemployed & $86(86)$ & $88(88)$ & \\
\hline Health Insurance & & & 0.134 \\
\hline Yes & $97(97)$ & $91(91)$ & \\
\hline No & $3(3)$ & $9(9)$ & \\
\hline Education level of spouse & & & 0.311 \\
\hline Elementary school & $57(57)$ & $62(62)$ & \\
\hline High school & $35(35)$ & $26(26)$ & \\
\hline University & $8(8)$ & $12(12)$ & \\
\hline Employment of spouse & 0.213 & & \\
\hline Employed & $97(97)$ & $92(92)$ & \\
\hline Unemployed & $3(3)$ & $8(8)$ & \\
\hline \multicolumn{4}{|l|}{ Monthly Income } \\
\hline (Turkish Lira) & & & 0.692 \\
\hline$\leq 1300$ & 51 & 57 & \\
\hline $1301-2999$ & 36 & 32 & \\
\hline$\geq 3000$ & 13 & 11 & \\
\hline Regular antepartum control & & & 0.680 \\
\hline Yes & $88(88)$ & $85(85)$ & \\
\hline No & $12(12)$ & $15(15)$ & \\
\hline
\end{tabular}


babies were reviewed, the numbers of baby boys and baby girls were found equal. While $49 \%$ of the babies in Group 1 were baby girls and $51 \%$ of them baby boys, $51 \%$ of the babies in Group 2 were baby girls and $49 \%$ of them baby boys, the difference being statistically insignificant $(\mathrm{p}=0.888)$.

\section{Latch Scores}

The mean total LATCH score of the mothers participating in the study was found to be $8.9 \pm 1.6$ (min 2-max 10). The mean total scores in subgroups were $1.7 \pm 0.6$ for latch, $1.7 \pm 0.6$ for audible swallowing, $1.9 \pm 0.4$ for type of nipple, $1.8 \pm 0.4$ for comfort (injury in nipple) and $1.8 \pm 0.4$ for holding the baby.

The mean total LATCH score was $9.5 \pm 1.0$ in the group trained by a midwife and $8.3 \pm 1.8$ in the group trained by an obstetrician, and the difference was statistically significant $(p<0.05)$. While there was no difference between the two groups in baby holding position ( $p>0.05$ ); the scores of latch, audible swallowing of the baby, type of nipple and mother's comfort concerning her nipple were significantly higher in Group $1(\mathrm{p}<0.05)$ (Table 2).

\section{Discussion}

According to our study results the mean total LATCH scores were found to be significantly higher in the group trained by a midwife. Except for the baby holding position, all other scores (latch, audible swallowing of the baby, type of nipple and mother's comfort concerning her nipple) were also significantly higher in the group trained by a midwife compared with the group trained by an obstetrician.

World Health Organization (WHO) and United Nations International Children's Emergency Fund (UNICEF) have been stressing in recent years the importance of starting breastfeeding babies within the first hour and feeding them exclusively with breast milk during the first 6 months. Although this point is specifically brought to attention and underlined, the rates of exclusive breastfeeding rates during the first 6 months are still away behind the expectations in both developed and developing countries worldwide (13). According to the UNICEF data, this rate has not changed across the world from the 1990 s to the date and remained at approximately $36 \%(13)$.
Intensive efforts are being made by the Ministry of Health to increase breastfeeding rate in our country. Such efforts include introduction of breastfeeding trainings within the scope of the 'Promoting Breast Milk and Baby-Friendly Healthcare Institutions Program', running a baby-friendly hospitals campaign and establishment of lactation counseling units. Despite these, the rates of initiation of breastfeeding within the first hour and exclusive breastfeeding for the first 6 months are still very low. According to the TNSA-2013 outcomes, only 50\% of babies were breastfed within the first hour after birth and the rate of exclusive breastfeeding in the first six months was found to be $30.1 \%$ (4). Therefore, although breastfeeding is widespread in our country, exclusive breastfeeding rates are still not at a satisfactory level. Early introduction of formula and other liquids and use of baby bottles and pacifiers are common. Breastfeeding-related problems such as late initiation of breastfeeding or discontinuation of it in a short time arise rarely from the unwillingness of mothers in this respect. Painful and injured nipples, mastitis, poor positioning of the baby to the breast and worries of the mother about having insufficient milk and inadequate nutrition of the baby usually emerges from insufficient knowledge of mothers about breastfeeding. These problems are the common causes of early cessation of breastfeeding and initiation of formula or supplemental food although not necessary $(5,14,15)$.

Besides the inadequacy of social support, unsatisfactory lactation counseling provided to mothers is also known to cause early cessation of breastfeeding (6). Successful breastfeeding starts when the mother thinks she is going to breastfeed her baby and believes that she can accomplish it. A mother who knows how to breastfeed becomes self-confident. Although there are many factors preventing early initiation and continuation of breastfeeding, one of the top reasons is that mothers have inadequate knowledge about both the importance of breast milk and the breastfeeding techniques and they are not being encouraged enough about breastfeeding.

Access to healthcare services has become easier in our country especially in recent years and the rate of antenatal care has reached the levels as high as $90 \%$. However, antenatal breastfeeding education, which has been shown in studies to be one of the major factors increasing the success in breastfeeding, has not become widespread yet $(16,17,18)$.

Table 2: Comparison of total LATCH and LATCH subgroup scores

\begin{tabular}{llll}
\hline & Grup 1 $(\mathrm{n}=100)$ & Grup 2 $(\mathrm{n}=100)$ & $p$ \\
\hline $\begin{array}{l}\text { Total LATCH scores } \\
\text { LATCH subgroup scores }\end{array}$ & $9.5 \pm 1.0$ & $8.3 \pm 1.8$ & 0.000 \\
$\quad$ & & & 0.000 \\
Latch & $1.8 \pm 0.3$ & $1.5 \pm 0.7$ & 0.000 \\
Audible Swallowing & $1.8 \pm 0.3$ & $1.5 \pm 0.7$ & 0.000 \\
$\quad$ Type of Nipple & $1.9 \pm 0.1$ & $1.7 \pm 0.5$ & 0.000 \\
Comfort of Breast/Nipple & $1.9 \pm 0.2$ & $1.6 \pm 0.5$ & 0.502 \\
Hold/Positioning & $1.8 \pm 0.3$ & $1.8 \pm 0.4$ & \\
\hline
\end{tabular}


In our hospital, a baby-friendly institution, all mothers are explained about the benefits of feeding with breast milk and given breastfeeding education after their delivery by midwives who received lactation consultancy education. There are efforts in our hospital in recent years to make lactation counseling widespread also among doctors in order to reduce the burden on midwives and to increase breastfeeding rates by providing breast milk and breastfeeding trainings not only after birth but also during routine pregnancy monitoring.

The importance of breastfeeding education given by health professionals who received special training in this area is obvious in the prevention and treatment of all ailments related to breastfeeding $(12,14)$. The effect of ante/postpartum breastfeeding education on increasing exclusive breastfeeding rates has been shown by several studies in literature $(12,19,20,21)$. In the common report prepared by the WHO and UNICEF on "Protecting, Promoting and Supporting Breastfeeding", attention is drawn to the importance of healthcare education and practices in adopting and lengthening breastfeeding, and the midwives who carry out mother-child healthcare services are assigned the duty of furnishing mothers with appropriate information on, and supporting them in, breastfeeding (22). In their study that aimed to determine the knowledge level of Turkish midwives and nurses on the benefits and characteristics of breast milk and infant feeding practices during the first six months of life, Karaçam and Kitis established that midwives and nurses had adequate level of knowledge and experience. However, they noted that midwives and nurses should be given continuous in-service training so that they can both update their knowledge and help reduce infant mortality, which is one of the priority targets of our country for the $21^{\text {st }}$ Century (23).

Midwives are seen as persons protecting, promoting and supporting breastfeeding in the society and healthcare sector. In the present study, we aimed to determine whether there was any difference in the breastfeeding success of the mothers who were given breastfeeding education with respect to the person giving the training. We found that the breastfeeding scores were significantly higher in the group that was trained by midwives after birth than in the group that was trained by obstetrician. There are many studies in the literature showing that the rates and duration of breastfeeding increases through the breastfeeding education and counseling given to mothers by midwives/nurses $(24,25,26,27)$. In their study where they compared breastfeeding success in 228 mothers who were given breastfeeding education by lactation nurses postpartum with 355 mothers who were not given any training, Jones and West determined that lactation nurses had an apparent impact in the extension of the duration of breastfeeding (24). In another study made by Jang et al. in a baby-friendly hospital in Korea, they found that the breastfeeding rates of the mothers who were given breastfeeding support by nurses in their postpartum periods were noticeably higher, which is similar to the findings of our study (27). Our study results showed that while there was no significant difference between the two groups in baby holding position; the scores of latch, audible swallowing of the baby, type of nipple and mother's comfort concerning her nipple were significantly higher in the group trained by midwives. In the study made by Aggarwal R and Aggarwal A in England where they investigated the influences of physicians, midwives and lactation consultants on solving the most important problems concerning breastfeeding such as type of nipple, problems of nipple and frequency of breastfeeding by administering a questionnaire consisting of these problems to each of these groups, they found that the scores of midwives and lactation consultants were distinctly higher than those of physicians (28). Similarly, in another study made in Israel on a population with a moderate level of income to explore the effect of breastfeeding education given by nurses in the perinatal period on the duration of breastfeeding, they found that the initiation rates of breastfeeding rose from $84 \%$ to $93 \%$, the average duration of breastfeeding was prolonged and the rates at which mothers were satisfied with this training increased from $43 \%$ to $79 \%$ (29). Breastfeeding education can be more effective when provided by those with whom the mother feels more comfortable, can more easily communicate and can more readily have contact. The results of a survey administered to 203 mothers in Scotland immediately after birth and at 6 weeks showed that nurses and midwives have a crucial role in communicating positive views on breastfeeding to new mothers at different time points (30).

Today, priority should be given to furnishing the health professionals who will be engaged in training, educating and supporting mothers with both adequate knowledge and skills, and proper communication skills within the scope of national breastfeeding policies of countries. Providing mothers proper breastfeeding education by a lactation consultant in both prenatal and postnatal periods is not extremely important in the initiation and sustaining of breastfeeding but also important in preventing breastfeeding problems. As they are more readily available to the patients and establish better communication with them, the training by midwives seems to be more effective for patients. The quality of the knowledge and skills of midwives regarding breast milk and breastfeeding is among the important factors in increasing breastfeeding rates and duration of breastfeeding to the desired levels. Midwives should keep in mind how important their roles are in breastfeeding.

The cross-sectional nature of the study, small number of subjects, the LATCH assessment scale being affected, even if a little, by the personal observations and interpretations of the person completing it and its being insufficient in measuring all details concerning breastfeeding are the limitations of our study and there is a need to conduct prospective studies with more heterogeneous groups and with larger number of participants to measure the significance of lactation consultancy and its contribution to breastfeeding rates in our country. 


\section{References}

1. Lopez Alvarez MJ. Proteins in human milk. Breastfeed Rev 2007;15(1):5-16.

2. Oddy WH. The impact of breastmilk on infant and child health. Breastfeed Rev 2002;10(3):5-18.

3. Oddy WH. Long-term health outcomes and mechanisms associated with breastfeeding. Expert Rev Pharmacoecon Outcomes Res 2002;2(2):161-77.

4. Türkiye Nüfus ve Sağlık Araştırması 2013. Hacettepe Üniversitesi Nüfus Etütleri Enstitüsü, Ankara, Türkiye.

5. Walker M. Management of selected early breastfeeding problems seen in clinical practice. Birth 1989;16(3):14858.

6. Riordan J, Gill-Hopple K. Breastfeeding care in multicultural populations. J Obstet Gynecol Neonatal Nurs 2001; 30(2):216-23.

7. Ego A, Dubos JP, Djavadzadeh-Amini M, Depinoy MP, Louyot J, Codaccioni X. Premature discontinuation of breastfeeding. Arch Pediatr 2003;10(1):11-8.

8. Nakao Y, Moji K, Honda S, Oishi K. Initiation of breastfeeding within 120 minutes after birth is associated with breastfeeding at four months among Japanese women: a self-administered questionnaire survey. Int Breastfeed J 2008;3(1):1.

9. Widström AM, Wahlberg V, Matthiesen AS, Eneroth P, Uvnäs-Moberg K, Werner S, Winberg J. Short-term effects of early suckling and touch of the nipple on maternal behaviour. Early Hum Dev 1990;21(3):153-63.

10. Jensen D, Wallace S, Kelsay P. LATCH: a breastfeeding charting system and documentation tool. J Obstet Gynecol Neonatal Nurs 1994;23(1):27-32.

11. Yenal K, Okumuş H. LATCH emzirme tanılama aracının güvenirliğini inceleyen bir çalışma. Hemşirelikte Araştırma Geliştirme Dergisi 2003;5(1):38-44.

12. Renfrew MJ, McCormick FM, Wade A, Quinn B, Dowswell T. Support for healthy breastfeeding mothers with healthy term babies. Cochrane Database Syst Rev 2012;5:CD001141.

13. United Nations Children's Fund (UNICEF) Breast Feeding On The Worldwide Agenda Findings from a landscape analysis on political commitment for programmes to protect, promote and support breastfeeding. NY USA:UNICEF; 2013.

14. Gerd AT, Bergman S, Dahlgren J, Roswall J, Alm B. Factors associated with discontinuation of breastfeeding before 1 month of age. Acta Paediatr 2012;101(1):55-60.

15. Alexander A, Dowling D, Furman L. What do pregnant low-income women say about breastfeeding? Breastfeed Med 2010;5(1):17-23.
16. Lin SS, Chien LY, Tai CJ, Lee CF. Effectiveness of a prenatal education programme on breastfeeding outcomes in Taiwan. J Clin Nurs 2008;17(3):296-303.

17. Forster D, McLachlan H, Lumley J, Beanland C, Waldenström U, Harris H, Earl D, Dyson K. ABFAB. Attachment to the breast and family attitudes to breastfeeding. The effect of breastfeeding education in the middle of pregnancy on the initiation and duration of breastfeeding: a randomised controlled trial (ISRCTN 21556494). BMC Pregnancy Childbirth 2003;3(1):5.

18. Duffy EP, Percival P, Kershaw E. Positive effects of an antenatal group teaching session on postnatal nipple pain, nipple trauma and breast feeding rates. Midwifery 1997; 13(4):189-96.

19. Thurman SE, Allen PJ. Integrating lactation consultants into primary health care services: are lactation consultants affecting breastfeeding success? Pediatr Nurs 2008;34(5): 419-25.

20. Britton C, McCormick FM, Renfrew MJ, Wade A, King SE. Support for breastfeeding mothers. Cochrane Database Syst Rev 2007;(1):CD001141.

21. Sikorski J, Renfrew MJ, Pindoria S, Wade A. Support for breastfeeding mothers. Cochrane Database Syst Rev 2002;(1):CD001141.

22. World Health Organisation, UNICEF. Protecting, promoting and supporting breast-feeding. The special role of maternity services. 1989.

23. Karaçam Z, Kitiş Y. What do midwives and nurses in Turkey know about nutrition in the first six months of life. Midwifery 2005;21(1):61-70.

24. Jones DA, West RR. Effect of a lactation nurse on the success of breast-feeding: a randomised controlled trial. J Epidemiol Community Health 1986;40(1):45-49.

25. Jones DA, West RR. Lactation nurse increases duration of breast feeding. Arch Dis Child 1985;60(8):772-774.

26. Osinaike A, Oyedeji GA, Olowe SA. The knowledge and breastfeeding of nurses and midwives in Ile-Ife and Ilesa concerning breastfeeding. J Trop Ped 1992;38(4):204.

27. Jang GJ, Kim SH, Jeong KS. Effect of postpartum breastfeeding support by nurse on the breast-feeding prevalence. Taehan Kanho Hakhoe Chi 2008;38(1):172-9.

28. Aggarwal R and Aggarwal A. Professional advice on common breastfeeding problems: a primary care study. Br J Gen Pract 1997;47(416):173-4.

29. Shinwell ES, Churgin Y, Shlomo M, Shani M, FlidelRimon $\mathrm{O}$. The effect of training nursery staff in breastfeeding guidance on the duration of breastfeeding in healthy term infants. Breastfeed Med 2006;1(4):247-52.

30. Swanson V, Power KG. Initiation and continuation of breastfeeding: theory of planned behaviour. J Adv Nurs 2005;50(3):272-82. 